Check for updates

Cite this: RSC Adv., 2019, 9, 28470

\title{
Triphala inhibits alpha-synuclein fibrillization and their interaction study by NMR provides insights into the self-association of the protein $\dagger$
}

\author{
Mandar Bopardikar, (D) anusri Bhattacharya, ${ }^{\mathrm{b}}$ Veera Mohana Rao Kakita, \\ Kavitha Rachineni, ${ }^{\mathrm{b}}$ Lalit C. Borde, ${ }^{\mathrm{C}}$ Sinjan Choudhary, (D) ${ }^{\mathrm{b}}$ Sri Rama Koti \\ Ainavarapu (D) *a and Ramakrishna V. Hosur (D)*ab
}

The process of assembly and accumulation of the intrinsically disordered protein (IDP), alpha-synuclein ( $\alpha$ Syn) into amyloid fibrils is a pathogenic process leading to several neurodegenerative disorders such as Parkinson's disease, multiple system atrophy and others. Although several molecules are known to inhibit aSyn fibrillization, the mechanism of inhibition is just beginning to emerge. Here, we report the inhibition of fibrillization of $\alpha$ Syn by Triphala, a herbal preparation in the traditional Indian medical system of Ayurveda. Triphala was found to be a rich source of polyphenols which are known to act as amyloid inhibitors. ThT fluorescence and TEM studies showed that Triphala inhibited the fibrillization of $\alpha$ Syn. However, it was observed that Triphala does not disaggregate preformed $\alpha$ Syn fibrils. Further, nativePAGE showed that Triphala reduces the propensity of aSyn to oligomerize during the lag phase of fibrillization. Our NMR results showed that certain stretches of residues in the N-terminal and NAC regions of $\alpha$ Syn play an anchor role in the self-association process of the protein, thereby providing mechanistic insights into the early events during $\alpha$ Syn fibrillization.

Received 18th July 2019

Accepted 31st August 2019

DOI: $10.1039 / \mathrm{c} 9 \mathrm{ra05551g}$

rsc.li/rsc-advances

\section{Introduction}

Alpha-synuclein ( $\alpha$ Syn), a 140 amino acid intrinsically disordered protein (IDP), ${ }^{1}$ is expressed in human neuronal cells. ${ }^{2}$ The accumulation of this protein in the form of fibrillar aggregates, which are the major constituents of Lewy bodies (LB), in the cytoplasm of dopaminergic neurons, is a characteristic of neurodegenerative disorders like Parkinson's disease (PD), Lewy body dementia (LBD), multiple system atrophy (MSA). ${ }^{3,4}$ The duplication or triplication of the gene encoding $\alpha$ Syn (SNCA) is linked to familial early onset PD. ${ }^{5}$

There is no preventive therapy available for $\mathrm{PD}$ as yet. However, small organic molecules capable of inhibiting $\alpha$ Syn fibrillization represent one of the potential therapeutic strategies for PD. In the past few years, several studies have reported the inhibition of $\alpha$ Syn fibrillization by small organic molecules. ${ }^{6-32}$ Interestingly, most of these molecules are polyphenols. In this context, we utilized a herbal preparation frequently used in the traditional medicinal system of India, commonly known as

${ }^{a}$ Department of Chemical Sciences, Tata Institute of Fundamental Research, Homi BhabhaRoad, Colaba, Mumbai 400005, India.E-mail: koti@tifr.res.in; rvhosur53@ gmail.com

${ }^{b} U M-D A E$ Centre for Excellence in Basic Sciences, University of Mumbai, Kalina Campus, Santacruz, Mumbai 400098, India

${ }^{c}$ Department of Biological Sciences, Tata Institute of Fundamental Research, Homi Bhabha Road, Colaba, Mumbai 400005, India

$\dagger$ Electronic supplementary information (ESI) available. See DOI: 10.1039/c9ra05551g
Ayurveda. The past couple of decades have witnessed an increase in the research on various herbal formulations prescribed by Ayurveda. ${ }^{33-37}$ The scientific validation of the pharmaceutical properties of these Ayurvedic formulations is beginning to emerge. $^{33-37}$ Triphala, an Ayurvedic formulation containing naturally occurring polyphenols, is known to possess a wide range of medicinal properties such as free radical scavenging, antioxidant, anti-inflammatory, antimutagenic, antistress, hypoglycaemic and radioprotective which have been recently reviewed. ${ }^{38}$ Some of these properties of Triphala are believed to be due to its polyphenolic constituents. ${ }^{39,40}$ Recently, aqueous extract of Triphala was found to inhibit cancer cell proliferation for HeLa, PANC-1 and MDA-MB-231 cell lines. ${ }^{41}$ However, a detailed chemical characterization of Triphala has not yet been reported. Therefore, in the current investigation, we performed a thorough chemical characterization of aqueous extract of Triphala. Indeed, Triphala is found to be abundant in polyphenolic content. Further, we analyzed Triphala for its ability to inhibit $\alpha$ Syn fibrillization as well as disaggregate preformed $\alpha$ Syn fibrils in vitro. We find that Triphala inhibits $\alpha$ Syn fibrillization, while it has no effect on preformed $\alpha$ Syn fibrils.

\section{Materials and methods}

\section{Preparation of aqueous extract of Triphala}

Triphala capsules were purchased from the Himalaya Drug Company, India. $20 \%$ (w/v) Triphala powder was suspended 
in Milli-Q water. This partially soluble sample was then heated to $65{ }^{\circ} \mathrm{C}$ for $30 \mathrm{~min}$. The sample was then centrifuged at $13000 \mathrm{rpm}$ and the soluble fraction was lyophilized with the help of a Labconco Free Zone 2.5 lyophilizer, USA. Required quantities of the lyophilized powder were weighed and dissolved in phosphate buffer saline (PBS) $(10 \mathrm{mM}$ $\mathrm{Na}_{2} \mathrm{HPO}_{4}, 1.8 \mathrm{mM} \mathrm{KH} \mathrm{PO}_{4}, 137 \mathrm{mM} \mathrm{NaCl}, 2.7 \mathrm{mM} \mathrm{KCl}$ and $0.01 \%(\mathrm{w} / \mathrm{v})$ sodium azide) $\mathrm{pH} 7.4$. The $\mathrm{pH}$ of the Triphala solution was adjusted to 7.4 before utilizing the sample for experiments.

\section{Protein overexpression and purification}

aSyn gene contained in the vector pT7-7 baring ampicillin resistance was expressed in Escherichia coli BL21 (DE3) cells. $10 \mathrm{ml}$ of LB containing $100 \mu \mathrm{g} \mathrm{ml} \mathrm{m}^{-1}$ of freshly prepared ampicillin was inoculated with the glycerol stock of over-expressed $\alpha$ Syn and grown overnight at $37{ }^{\circ} \mathrm{C}$ with shaking $(180 \mathrm{rpm})$. $10 \mathrm{ml}$ (1\% inoculum) of the overnight culture was then transferred to 1 litre of LB or M9 culture containing $100 \mu \mathrm{g} \mathrm{ml}$ ampicillin and allowed to grow till an $\mathrm{OD}_{600}$ of 0.8-1.0. Subsequently, the culture was induced with $1 \mathrm{mM}$ IPTG for 6-10 h. Finally, the culture was centrifuged to obtain a cell pellet which was stored at $-80{ }^{\circ} \mathrm{C}$. $\alpha$ Syn was purified by a previously reported non-chromatographic method. ${ }^{42,43}$ Briefly, frozen cell pellets were resuspended in Tris buffer (50 mM Tris, $10 \mathrm{mM}$ EDTA and $150 \mathrm{mM} \mathrm{NaCl}$ ) pH 8 and sonicated for $10 \mathrm{~min}$. The suspension was placed in a boiling water-bath for $20 \mathrm{~min}$ and then centrifuged for $10 \mathrm{~min}$. The supernatant was collected into a fresh tube and streptomycin sulfate $(136 \mu \mathrm{l}$ of $10 \%$ solution/ml of supernatant) and glacial acetic acid ( $228 \mu \mathrm{l} \mathrm{ml}^{-1}$ of supernatant) were added followed by centrifugation for $10 \mathrm{~min}$. Again, the supernatant was collected and then precipitated with saturated ammonium sulfate which was added as $1: 1(\mathrm{v} / \mathrm{v})$ to supernatant. Precipitated protein was washed with ammonium sulfate solution (1:1 (v/v) saturated ammonium sulfate and water). The pellet was resuspended in $3 \mathrm{ml}$ of $100 \mathrm{mM}$ ammonium acetate and precipitated with addition of an equal volume of ethanol. Resuspension in ammonium acetate and precipitation in ethanol was repeated twice more. Finally, the pellet was resuspended in $100 \mathrm{mM}$ ammonium acetate, followed by freezing in liquid nitrogen and lyophilization. Pure aSyn was obtained as confirmed by mass spectrometry (Fig. S1†).

\section{aSyn amyloid fibril formation}

The fibrillization reaction was commenced with $150 \mu \mathrm{M}$ small oligomeric $\alpha$ Syn in $2 \mathrm{ml}$ Protein LoBind Eppendorf tube in PBS $\mathrm{pH}$ 7.4. This protein sample either in the presence or absence of various concentrations of Triphala was subjected to mechanical agitation at $65 \mathrm{rpm}$ and $37^{\circ} \mathrm{C} .5 \mu \mathrm{l}$ aliquots were withdrawn from the fibrillating $\alpha$ Syn sample at various intervals of time. Each aliquot was uniformly mixed with $245 \mu \mathrm{l}$ of $25 \mu \mathrm{M}$ ThT solution in PBS pH 7.4 and fluorescence was immediately recorded with the help of an Agilent spectrofluorometer with excitation at $444 \mathrm{~nm}$ and emission from 455 to $500 \mathrm{~nm}$. Both the excitation and emission slit widths were $5 \mathrm{~nm}$ for all the measurements. The fluorescence intensity at $485 \mathrm{~nm}$ was plotted against time.

\section{Transmission electron microscopy (TEM)}

aSyn samples at the end of fibrillization (198 h) were diluted to $30 \mu \mathrm{M}$ in distilled water. These were spotted onto a carboncoated Formvar grid, incubated for $5 \mathrm{~min}$, stained with a freshly prepared $1 \%(\mathrm{w} / \mathrm{v})$ aqueous solution of uranyl acetate filtered through $0.22 \mu \mathrm{m}$ syringe filter by incubating for $1 \mathrm{~min}$ and then finally washed with distilled water. The samples were then imaged on a Libra 120EFTEM electron microscope from Carl Zeiss (Germany).

\section{Circular dichroism (CD) spectroscopy}

In order to monitor the changes in secondary structural features during $\alpha$ Syn fibrillization, far UV CD spectra were recorded at different time intervals. All the spectra were recorded on a Jasco J-1500 spectropolarimeter. The spectra were acquired in the wavelength range of 200-250 $\mathrm{nm}$. Six scans were obtained and averaged to produce each spectrum. Each spectrum was baseline corrected by subtracting the buffer or Triphala signal.

\section{Nuclear magnetic resonance (NMR) spectroscopy}

All the experiments were performed on a $800 \mathrm{MHz}$ Bruker Avance NMR spectrometer. ${ }^{1} \mathrm{H}-{ }^{15} \mathrm{~N}$ HSQC spectra were recorded for $150 \mu \mathrm{M}^{15} \mathrm{~N}$ isotopically enriched $\alpha$ Syn in PBS pH 7.4 in the presence and absence of $0.75 \mathrm{mg} \mathrm{ml}^{-1}$ Triphala. The 2D data was collected with 256 complex data points along the indirect dimension. Both the samples were incubated overnight at $37{ }^{\circ} \mathrm{C}$ under fibrillating condition prior to HSQC experiment. The temperature for the experiments was $25{ }^{\circ} \mathrm{C}$. Spectra were recorded in phase-sensitive mode and quadrature detection was performed with the help of States-TPPI method. ${ }^{44}$ Data was processed with the help of Topspin 3.5 (Bruker, USA) and analysed with CARA (Computer-Aided Resonance Assignment, Institute for Molecular Biology and Biophysics, Zurich, Switzerland). Chemical shift assignments were obtained by transfer from BMRB (accession number 16300) and other previous reports. ${ }^{45,46}$ Chemical shift perturbations (CSP) were calculated as $\left(\delta_{\mathrm{H}}{ }^{2}+0.1\left(\delta_{\mathrm{N}}{ }^{2}\right)\right)^{1 / 2},{ }^{47}$ where $\delta_{\mathrm{N}}$ and $\delta_{\mathrm{H}}$ represent the difference in the nitrogen and proton chemical shifts of $\alpha$ Syn in the presence of Triphala with respect to that of free $\alpha$ Syn, respectively.

\section{Native-polyacrylamide gel electrophoresis (native-PAGE)}

$\alpha \operatorname{Syn}(100 \mu \mathrm{M})$ was incubated overnight with or without $0.75 \mathrm{mg}$ $\mathrm{ml}^{-1}$ Triphala at $37{ }^{\circ} \mathrm{C}$ under agitation. After the incubation period, $12 \mu \mathrm{l}$ aliquots were withdrawn from each of the samples, thoroughly mixed with $3 \mu \mathrm{l}$ of staining dye (containing no SDS) and loaded on to an $11 \%$ polyacrylamide gel (prepared without the addition of SDS). Electrophoresis was carried out at $90 \mathrm{~V}$. Various species which were resolved on the gel, were then visualized by Coomassie staining. 


\section{Results and discussion}

\section{Triphala is rich in polyphenols}

Extensive chemical characterization of aq. Triphala extract (referred to as Triphala from here onwards) was performed with the help of LC-MS. A detailed list of the chemical constituents that were detected is provided, including the polyphenols (Table S1 $\dagger$ ) and other constituents (Table S2 $\dagger$ ). Here it is worth noting that quercetin is one of the constituents of Triphala, which has been previously reported to inhibit $\alpha$ Syn fibrillization. ${ }^{7,11}$ However, in $0.5 \mathrm{mg} \mathrm{ml}^{-1}$ Triphala, the concentration of quercetin comes out to be $\approx 5 \mu \mathrm{M}$ which is far less than what would be required for inhibiting the aggregation of $150 \mu \mathrm{M}$ $\alpha$ Syn. ${ }^{7,11}$

\section{Triphala inhibits $\alpha$ Syn fibrillization}

The process of fibrillization of $\alpha$ Syn was monitored in the presence of varying concentrations of Triphala with the help of thioflavin $\mathrm{T}$ (ThT) binding assay ${ }^{4-50}$ in a time-dependent manner. $\alpha$ Syn fibrillization when probed by ThT fluorescence shows a sigmoidal curve which is characterized by three different phases namely, nucleation, elongation and saturation phase..$^{51}$ It was observed that ThT fluorescence systematically decreased with an increase in the concentration of Triphala (Fig. 1A). Particularly, in the saturation phase of the aSyn fibrillization process, the ThT fluorescence intensity decreased consistently with an increase in the concentration of Triphala (Fig. S2 $\dagger$ ). In order to study if the process of fibril formation initiated at a time point beyond the duration shown in (Fig. 1A), ThT fluorescence was collected up to $330 \mathrm{~h}$ (Fig. S3†). However, no increase in ThT fluorescence was observed for $\alpha$ Syn in the presence of $0.5 \mathrm{mg} \mathrm{ml}^{-1}$ Triphala (Fig. S3 $\dagger$ ). It appeared that $0.5 \mathrm{mg} \mathrm{ml}^{-1}$ Triphala was capable of completely inhibiting $\alpha$ Syn fibrillization (Fig. 1A). However, there is a possibility that Triphala might interfere with ThT fluorescence. Therefore, transmission electron microscopy (TEM) studies were performed. It
A

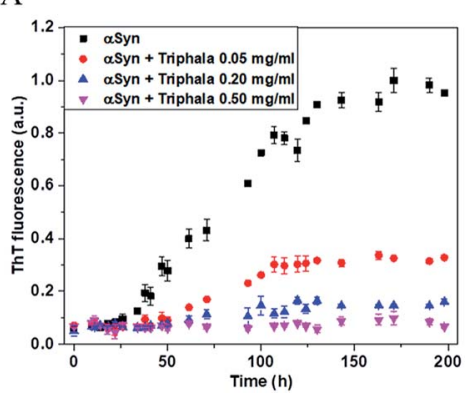

B

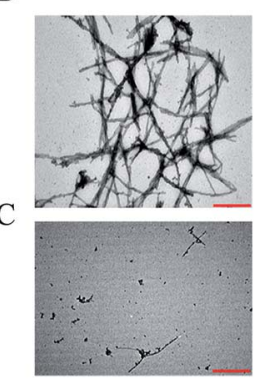

Fig. 1 Effect of Triphala on the fibrillization of aSyn. (A) The timecourse of the fibrillization of $150 \mu \mathrm{M} \alpha \mathrm{Syn}$ in the presence of different concentrations of Triphala monitored by ThT fluorescence. ThT fluorescence saturates to different levels in a Triphala concentrationdependent manner. Each data point was an average of two independent measurements. The error bars are SD. (B and C) Morphological characterization of the effect of Triphala on $\alpha$ Syn. TEM images of $\alpha$ Syn at the end of fibrillization reaction in the absence (B) and presence (C) of $0.5 \mathrm{mg} \mathrm{ml}^{-1}$ Triphala. The scale bar is $500 \mathrm{~nm}$ in panels (B) and (C). was observed that $0.5 \mathrm{mg} \mathrm{ml}^{-1}$ Triphala almost completely prohibited the formation of $\alpha$ Syn fibrils for $150 \mu \mathrm{M}$ of the protein (Fig. 1B and C). Since a TEM image shows only a small region on the grid, therefore different regions on each grid were imaged (Fig. S4 $\dagger$ ). This comparison clearly shows the inhibitory effect of $0.5 \mathrm{mg} \mathrm{ml}^{-1}$ Triphala on the fibrillization of $150 \mu \mathrm{M}$ aSyn (Fig. S4†).

Triphala prevents 'random coil to $\beta$-sheet' structural transition essential for $\alpha$ Syn fibrillization

In order to investigate the effect of Triphala on the secondary structure of $\alpha$ Syn, far UV circular dichroism (CD) spectra were recorded for aSyn under fibrillating conditions in a timedependent manner, both in the presence and the absence of $0.75 \mathrm{mg} \mathrm{ml}^{-1}$ Triphala (Fig. 2). Initially, $\alpha$ Syn was observed to be largely random coil $(\approx 58 \%)$ as calculated by BESTSEL deconvolution algorithm (Fig. 2A and Table S3 $\dagger$ ). ${ }^{52,53}$ However, minor anti-parallel $\beta$-sheet content $(\approx 24 \%$ ) was also observed (Table $\mathrm{S} 3 \dagger)$. This observation of a major random coil along with a minor anti-parallel $\beta$-sheet conformation of $\alpha$ Syn is consistent with earlier reports. ${ }^{54,55}$ A clear structural transition from random coil to $\beta$-sheet was observed for $\alpha$ Syn after 37 hours of incubation under fibrillating condition (Fig. 2A). At this point in time, it was found that $\alpha$ Syn developed minor parallel $\beta$-sheet content which steadily increased with the passage of time (Table S3†). In this context, our results are in agreement with previous findings by Chakraborty et al. ${ }^{25}$ and Celej et al. ${ }^{56}$ where

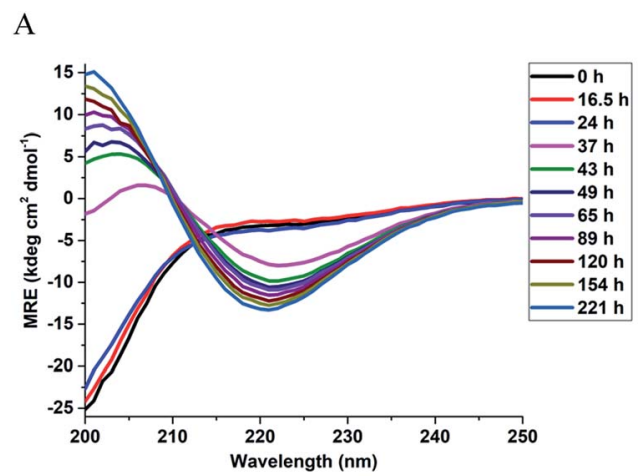

B

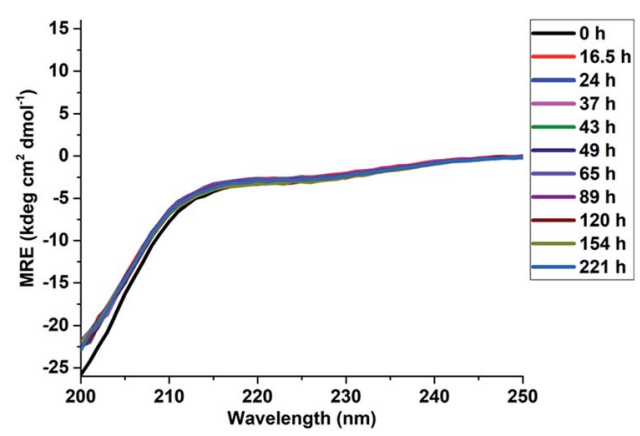

Fig. 2 Effect of Triphala on the secondary structure of $\alpha$ Syn. The time evolution of the secondary structure of $150 \mu \mathrm{M} \alpha$ Syn during fibrillization in the absence (A) and presence (B) of $0.75 \mathrm{mg} \mathrm{ml}^{-1}$ Triphala studied using CD spectroscopy. 
it was reported that $\alpha$ Syn fibrillization is characterized by 'random coil $\rightarrow$ anti-parallel $\beta$-sheet $\rightarrow$ parallel $\beta$-sheet' secondary structural changes, however, differ from the results obtained by Ghosh et al.,,$^{57}$ where it was observed that $\alpha$ Syn, forms fibrils via an $\alpha$-helix rich intermediate. On the other hand, in the presence of $0.75 \mathrm{mg} \mathrm{ml}^{-1}$ Triphala, $\alpha$ Syn did not show any structural change even up to 22 days of incubation and remained largely random coil (Fig. 2B and Table S3†). This suggests that the presence of Triphala causes stabilization of $\alpha$ Syn in its natively unfolded conformation.

\section{Triphala influences the self-association of $\alpha$ Syn and reduces its oligomerization propensity}

The observation that Triphala hinders the fibrillization of $\alpha$ Syn raises the question as to how and by what mechanism? In this respect, NMR and native-PAGE have provided valuable insight into the mechanism lying underneath. ${ }^{1} \mathrm{H}-{ }^{15} \mathrm{~N}$ HSQC spectra (Fig. $3 \mathrm{~A}$ ) were recorded for $\alpha$ Syn in the presence and absence of $0.75 \mathrm{mg} \mathrm{ml}^{-1}$ of Triphala under fibrillating conditions in the lag phase (see Materials and methods). The individual spectra along with a spectrum recorded under identical conditions in the presence of $0.5 \mathrm{mg} \mathrm{ml}^{-1}$ Triphala (Fig. S5 $\dagger$ ) show a systematic change in the $\alpha$ Syn HSQC spectrum with increase in
Triphala concentration. A comparative analysis of the spectra (shown in Fig. 3A) revealed interesting features: (i) absence of several peaks in the $\alpha$ Syn spectrum (in red) which appeared in the presence of Triphala (spectrum in blue). (ii) The residues for which peaks have vanished in the $\alpha$ Syn spectrum belong to the non-amyloid- $\beta$ component (NAC) and N-terminal regions. A close inspection of these peaks reveals that they belong to sequential stretches of residues along the $\alpha$ Syn primary sequence: (a) T72, G73, T75 and A76; (b) T81, G84, G86 and S87; (c) T64, V66, G67, G68, A69; (d) A53, T54; (e) G41, K43, T44; (f) T92, G93; (g) G31, T33. (iii) It is to be noted that all these stretches contain primarily threonine and serine residues and their neighboring residues along the sequence. (iv) Chemical shift perturbation (CSP) measurements for the peaks which were present in both the spectra (Fig. 3B) showed insignificant peak shift due to the presence of Triphala. ( $\mathrm{v}$ ) The presence of Triphala caused an increase in the peak intensities for residues in the N-terminal and NAC regions (Fig. 3C). On the other hand, the intensities for C-terminal residues were found to be decreased in the presence of Triphala (Fig. 3C).

It may be mentioned here that the absence of peaks cannot be attributed to chemical exchange between the backbone amide protons and water (solvent) for the following reasons:
A

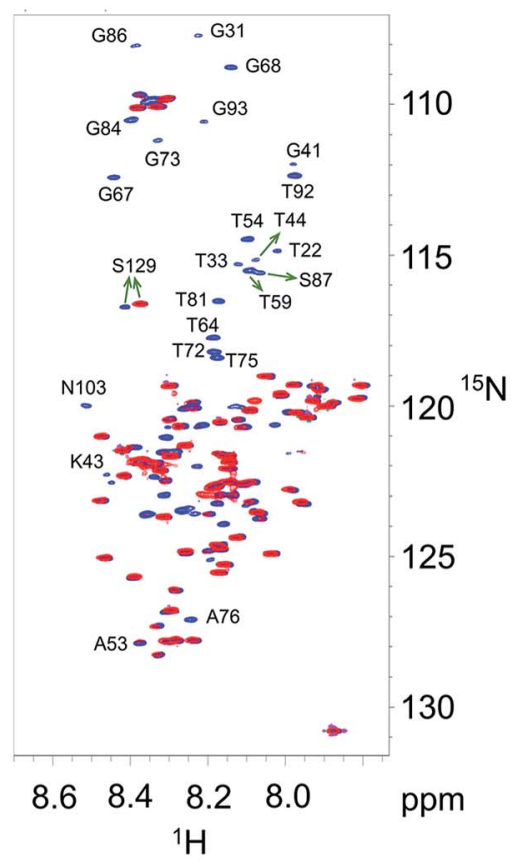

B

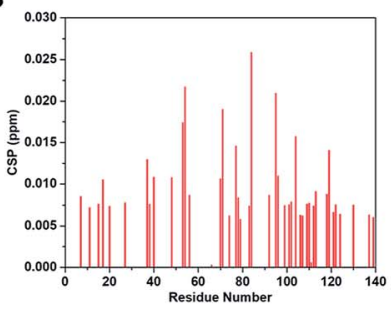

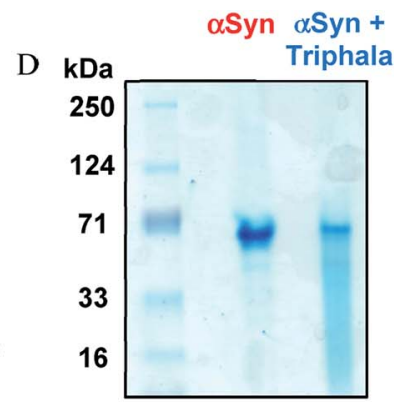

$\mathrm{C}$

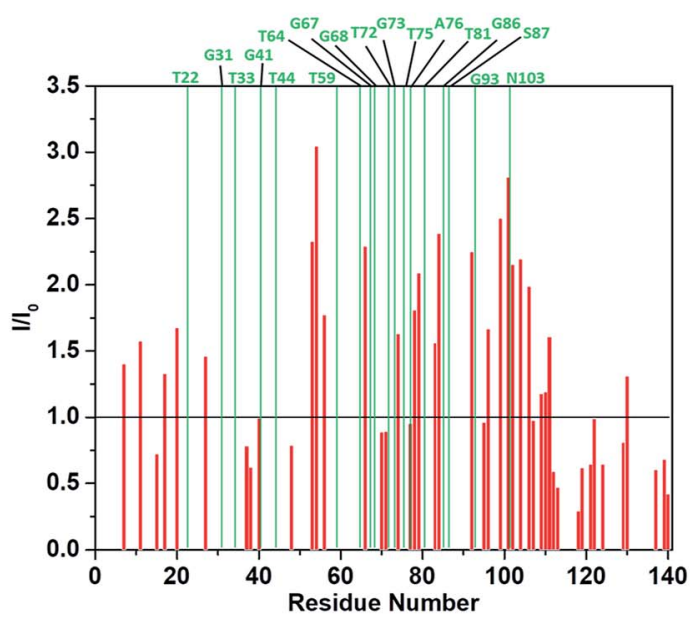

Fig. 3 Mode of interaction of Triphala with $\alpha$ Syn and its effect on the early self-association of $\alpha$ Syn. (A) ${ }^{1} \mathrm{H}-{ }^{15} \mathrm{~N} \mathrm{HSQC} \mathrm{spectrum} \mathrm{of} \alpha$ Syn in the presence (blue) and absence (red) of $0.75 \mathrm{mg} \mathrm{ml}^{-1}$ Triphala. The peaks were assigned by transfer of assignments from BMRB (accession number 16300) and other previous reports. ${ }^{45,46}$ (B) Chemical shift perturbation (CSP) for $150 \mu \mathrm{M} \alpha$ Syn observed in ${ }^{1} \mathrm{H}-{ }^{15} \mathrm{~N} \mathrm{HSQC}$ spectra in the presence of $0.75 \mathrm{mg} \mathrm{ml}^{-1}$ Triphala relative to free $\alpha$ Syn. (C) Ratios of the peak heights of $150 \mu \mathrm{M} \alpha$ Syn observed in ${ }^{1} \mathrm{H}-{ }^{15} \mathrm{~N} \mathrm{HSQC} \mathrm{spectra} \mathrm{in} \mathrm{the} \mathrm{presence} \mathrm{of}$ $0.75 \mathrm{mg} \mathrm{ml}^{-1}$ Triphala relative to peak heights in $\alpha \operatorname{Syn}{ }^{1} \mathrm{H}-{ }^{15} \mathrm{~N}$ HSQC spectrum in the absence of Triphala are shown as red bars. The green bars indicate residues which were absent in ${ }^{1} \mathrm{H}-{ }^{15} \mathrm{~N} H S Q C$ spectrum of $\alpha$ Syn. (D) Native-PAGE gel showing the oligomerization status of $\alpha$ Syn in both the absence as well as the presence of $0.75 \mathrm{mg} \mathrm{ml}^{-1}$ Triphala. 
a backbone amide ${ }^{1} \mathrm{H}$ resonance will be broadened due to exchange with water if $k_{\mathrm{ex}} \approx\left|\Omega_{\mathrm{NH}}-\Omega_{\mathrm{H}_{2} \mathrm{O}}\right|,{ }^{58}$ where $k_{\mathrm{ex}}=$ rate of exchange, $\Omega_{\mathrm{NH}}=$ amide ${ }^{1} \mathrm{H}$ frequency and $\Omega_{\mathrm{H}_{2} \mathrm{O}}=$ water ${ }^{1} \mathrm{H}$ frequency. For $\alpha \operatorname{Syn}, \Omega_{\mathrm{NH}}$ varies within the range of 8.7 to 7.7 (ppm) (Fig. 3A). Accordingly, average $\Omega_{\mathrm{NH}}$ turns out to be 8.2 (ppm). $\Omega_{\mathrm{H}_{2} \mathrm{O}}$ is equal to 4.7 (ppm). The difference turns out to be $3.5(\mathrm{ppm})$, which for a basic ${ }^{1} \mathrm{H}$ larmor frequency of $800(\mathrm{MHz})$, equals $2800\left(\mathrm{~s}^{-1}\right)$. Now $k_{\mathrm{ex}}$ values for the residues in $\alpha$ Syn have been explicitly measured by Bhattacharyya et al. ${ }^{59}$ under similar conditions, and they turn out to be extremely slow $\left(<8 \mathrm{~s}^{-1}\right)$. Hence, it is clear that $k_{\mathrm{ex}} \ll\left|\Omega_{\mathrm{NH}}-\Omega_{\mathrm{H}_{2} \mathrm{O}}\right|$, and hence exchange with solvent cannot account for vanishing of peaks. Now it is known that $\alpha$ Syn exists in oligomeric form during the lag phase of fibrillization process..$^{5,57,60-74}$ So then a question arises that is the disappearance of peaks for stretches of residues in the free aSyn HSQC spectrum (Fig. 3A) due to the oligomerization of the protein? If the answer to this question turns out to be yes, then the fact that these peaks appear in the presence of Triphala would mean Triphala is reducing the capability of the protein to oligomerize. In order to address the above question, nativePAGE was performed for $\alpha$ Syn samples in both the absence as well as presence of Triphala. Untreated $\alpha$ Syn was observed to migrate at $\approx 70 \mathrm{kDa}$ (Fig. 3D). Monomeric $\alpha$ Syn has been previously shown to migrate at $\approx 16 \mathrm{kDa}$ in native-PAGE experiments. $^{67,75}$ This suggests that major $\alpha$ Syn population is an oligomer, possibly tetramer, under our experimental conditions. Whereas, in the presence of Triphala, a large smear was observed in the lower molecular mass region starting from the main oligomer band $(\approx 70 \mathrm{kDa})$ right up to the expected monomer mass of $\approx 16 \mathrm{kDa}$ (Fig. 3D). In order to check for the possibility of protein degradation due to Triphala, mass spectrum of $\alpha$ Syn was obtained both with and without Triphala (Fig. S6†). The spectra appear to be very similar which indicates that Triphala does not cause degradation of $\alpha$ Syn (Fig. S6 $\dagger$ ). The presence of a continuous smear rather than discrete bands (Fig. 3D) could be due to (i) the existence of equilibrium between the oligomers of different sizes and monomer (ii) the binding of a varying number of Triphala constituents to $\alpha$ Syn or (iii) the prevalence of both (i) and (ii). The native gel (Fig. 3D) clearly shows that treatment with Triphala causes a breakdown of oligomeric aSyn into smaller oligomers and monomer. These observations suggest that the disappearance of peaks in HSQC spectrum for untreated $\alpha$ Syn (Fig. 3A) is due to a major oligomer population, where the peaks come from the locally flexible residues. Whereas, the peaks for the stretches of residues in the $\mathrm{N}$-terminal and NAC regions (mentioned above) which participate in the formation of the monomer-monomer contacts that are responsible for the integrity of the oligomer vanish from the spectrum (Fig. 3A). A schematic for $\alpha$ Syn oligomer is shown (Fig. 4). The red cylinders represent the following stretches of residues: (i) G31, T33 (ii) G41, K43, T44 (iii) A53, T54 (iv) T64, V66, G67, G68, A69 (v) T72, G73, T75, A76 (vi) T81, G84, G86, S87 (vii) T92, G93 (Fig. 4). It is these regions which are probably responsible for the formation of monomer-monomer contacts leading to the formation of oligomers (Fig. 4). The various regions along the primary sequence of $\alpha$ Syn are shown (Fig. S7A $\dagger$ ) and the above stretches of residues (represented as

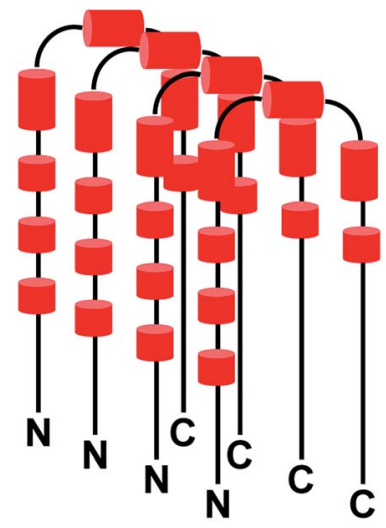

Fig. 4 Schematic for $\alpha$ Syn oligomer. The black solid lines depict flexible regions within the oligomer. The red cylinders represent different regions responsible for the formation of monomer-monomer contacts within the oligomer as observed in HSQC experiments. ' $\mathrm{N}$ ' and ' $\mathrm{C}$ ' represent the $\mathrm{N}$ - and $\mathrm{C}$-terminals respectively.

red cylinders in Fig. 4) are highlighted (Fig. S7B $\dagger$ ). It can be seen that these residues belong to the N-terminal and NAC regions. Triphala probably interferes in the formation of these interactions, as evident from the appearance of the peaks for these stretches of residues in the HSQC spectrum (Fig. 3A). The low CSP values suggest that the reduction in the ability of $\alpha$ Syn to oligomerize is brought about by the Triphala constituents by mode of weak interactions (Fig. 3B). On the other hand, the ratio of HSQC peak intensities (Fig. 3C) indicate that some of the Triphala constituents probably also interact with C-terminal residues causing an inhomogeneous broadening as is evident from the decrease in the peak intensities due to the presence of Triphala (Fig. 3C). This is particularly clear from the splitting of S129 into two peaks (Fig. 3C) in the presence of Triphala which is likely to be due to the slow exchange between bound and unbound state. ${ }^{58}$ For the other C-terminal residues, the peak splitting could be small compared to the spectral resolution and hence, causes an inhomogeneous peak broadening instead of showing up as two separate peaks.

\section{Triphala does not disaggregate $\alpha$ Syn amyloid fibrils}

It has been shown earlier that Triphala breaks down lysozyme fibrils into smaller and thinner fibrils. ${ }^{76}$ Therefore, in order to check the stability of $\alpha$ Syn fibrils in the presence of Triphala, preformed fibriller $\alpha$ Syn was incubated with $0.5 \mathrm{mg} \mathrm{ml}^{-1}$ Triphala. A spontaneous decrease in ThT fluorescence was observed upon the introduction of $0.5 \mathrm{mg} \mathrm{ml} \mathrm{m}^{-1}$ Triphala to prefibrillized $\alpha$ Syn (Fig. S8 $\dagger$ ). This suggested that Triphala may be capable of destabilizing $\alpha$ Syn fibrils. In order to confirm the above possibility, TEM images were recorded. Prefibrillized aSyn after treatment with $0.5 \mathrm{mg} \mathrm{ml}^{-1}$ Triphala did not show any significant change in the morphology, shape or size of the fibrils even after incubation for a period of 5 and half days (Fig. S9†). These results showed that $0.5 \mathrm{mg} \mathrm{ml}^{-1}$ Triphala is not capable of disaggregating $\alpha$ Syn fibrils. In view of these results, the decrease in ThT fluorescence upon addition of Triphala (Fig. S8†) could be due to (i) competitive binding of ThT and 
Triphala with $\alpha$ Syn fibrils or (ii) inner filter effect (Triphala might absorb in the region 400-450 nm, where ThT also absorbs). However, it was observed that Triphala does not absorb in this region (Fig. S10 $\dagger$ ). Therefore, the decrease in ThT fluorescence upon addition of Triphala (Fig. S8†) may be attributed to competitive binding of ThT and Triphala with aSyn fibrils.

In order to check if a higher concentration of Triphala is required to cause disaggregation of $\alpha$ Syn fibrils, the fibrils were treated with $2.5 \mathrm{mg} \mathrm{ml}^{-1}$ Triphala. The effect of $2.5 \mathrm{mg} \mathrm{ml}^{-1}$ Triphala on $\alpha$ Syn fibrils was monitored in a time-dependent manner by far-UV CD spectroscopy. Fibriller $\alpha$ Syn showed a global minimum at $220 \mathrm{~nm}$ which is characteristic of $\beta$-sheet secondary structure as expected for amyloid fibrils (Fig. S11 $)$ ). However, upon addition of Triphala, no change whatsoever was observed in the $\beta$-sheet character of fibrillar $\alpha$ Syn even after 5 and half days of incubation time (Fig. S11 $\dagger$ ). This suggested that even $2.5 \mathrm{mg} \mathrm{ml}^{-1}$ Triphala may not be capable of destabilizing aSyn fibrils. In order to see if this higher concentration of Triphala caused any minor changes in the morphology of $\alpha$ Syn fibrils without leading to any detectable changes in their secondary structure, TEM images were taken. It was observed that the rod-like filamentous shape of the fibrils remained unchanged (Fig. S12†). The width of the fibrils was found to be the same $(\approx 13 \mathrm{~nm})$ in the presence and absence of Triphala (Fig. S12 $\dagger$ ). These results indicate that even a high concentration i.e. $2.5 \mathrm{mg} \mathrm{ml}^{-1}$ of Triphala does not disaggregate preformed aSyn fibrils. In order to understand why Triphala is incapable of disaggregating preformed $\alpha$ Syn fibrils, it is important to know the residues of $\alpha$ Syn which interact with Triphala. As discussed above, certain stretches of residues of aSyn are responsible for oligomerization (Fig. S7B $\dagger$ ) and Triphala probably interacts with these regions and thus arrests oligomerization of $\alpha$ Syn. Now, in the fibriller state of $\alpha$ Syn, the residues which form the fibril core are known ${ }^{77}$ and are highlighted along the primary sequence of $\alpha$ Syn (Fig. S7C $\dagger$ ). A comparison of the residues (Fig. S7B and $\mathrm{C} \dagger$ ) suggests that the ones which interact with Triphala in the native state of $\alpha$ Syn are not available in the fibriller state of the protein since they are buried in the fibril core. Probably it is the inaccessibility of these residues, in the fibriller state, which is responsible for Triphala being incapable of disaggregating $\alpha$ Syn fibrils.

\section{Conclusions}

In summary, aqueous extract of Triphala, a natural herbal preparation has been shown to inhibit fibrillization of $\alpha$ Syn. While various biophysical tools have been used to study the course of $\alpha$ Syn fibrillization, NMR analysis of the effect of Triphala on the process have yielded insights into the nature of the residues involved in the self-association of $\alpha$ Syn leading to the formation of oligomers, which is one of the early events preceding the formation of mature amyloid fibrils. We demonstrate that stretches of residues which lie in the $\mathrm{N}$ terminal and the NAC regions of the protein chain play important role in the early association process, and the Triphala components, rich in polyphenols, interfere with this association. It is likely that different polyphenol components of Triphala act in a synergistic manner to bring about the arrest of $\alpha$ Syn self-association. Our results clearly state that Triphala has a wealth of molecules which are amyloid inhibitors. Future studies will determine the particular constituents which are responsible for bringing about the inhibition of $\alpha$ Syn fibrillization.

\section{Conflicts of interest}

There are no conflicts to declare.

\section{Acknowledgements}

The authors are thankful to Tata Institute of Fundamental Research (TIFR), Department of Atomic Energy (DAE) for financial support. R. V. H. is a DAE sponsored Raja Ramanna Fellow. $\alpha$ Syn plasmid was a kind gift from Vinod Subramaniam, Vrije Universiteit Amsterdam. Mass Spectrometry analysis was performed at the DBT-BIRAC supported Center for Applications of Mass Spectrometry (CAMS) at Venture Center BioIncubator at CSIR-NCL, Pune, India. The authors thank Francois-Xavier Theillet and Christian Griesinger for fruitful discussions. The authors acknowledge Shreyada Save, UM-DAE CEBS, Mumbai 400098, India, for her help in ThT fluorescence experiments. The authors are thankful to Mamata Kombrabail, Department of Chemical Sciences, TIFR, Mumbai 400005, India, for her help in CD and fluorescence experiments. The authors would like to thank Shrabasti Bhattacharya and Vaibhav Shukla for their inputs on CD experiments and CD data analysis. The authors are also grateful to Geetanjali Dhotre for helping with MALDI experiments and mass calibration.

\section{References}

1 P. H. Weinreb, W. Zhen, A. W. Poon, K. A. Conway and P. T. Lansbury Jr, Biochemistry, 1996, 35, 13709-13715.

2 D. F. Clayton and J. M. George, Trends Neurosci., 1998, 21, 249-254.

3 J. Q. Trojanowski, M. Goedert, T. Iwatsubo and V. M. Lee, Cell Death Differ., 1998, 5, 832-837.

4 M. Hashimoto and E. Masliah, Brain Pathol., 1999, 9, 707720.

5 A. B. Singleton, M. Farrer, J. Johnson, A. Singleton, S. Hague, J. Kachergus, M. Hulihan, T. Peuralinna, A. Dutra, R. Nussbaum, S. Lincoln, A. Crawley, M. Hanson, D. Maraganore, C. Adler, M. R. Cookson, M. Muenter, M. Baptista, D. Miller, J. Blancato, J. Hardy and K. GwinnHardy, Science, 2003, 302, 841.

6 K. A. Conway, J. C. Rochet, R. M. Bieganski and P. T. Lansbury Jr, Science, 2001, 294, 1346-1349.

7 M. Zhu, S. Han and A. L. Fink, Biochim. Biophys. Acta, 2013, 1830, 2872-2881.

8 M. Caruana, T. Högen, J. Levin, A. Hillmer, A. Giese and N. Vassallo, FEBS Lett., 2011, 585, 1113-1120.

9 J. Li, M. Zhu, S. Rajamani, V. N. Uversky and A. L. Fink, Chem. Biol., 2004, 11, 1513-1521. 
10 B. Ahmad and L. J. Lapidus, J. Biol. Chem., 2012, 287, 91939199.

11 X. Meng, L. A. Munishkina, A. L. Fink and V. N. Uversky, Parkinson's Dis., 2010, 1-16, DOI: 10.4061/2010/650794.

12 X. Meng, L. A. Munishkina, A. L. Fink and V. N. Uversky, Biochemistry, 2009, 48, 8206-8224.

13 D. E. Ehrnhoefer, J. Bieschke, A. Boeddrich, M. Herbst, L. Masino, R. Lurz, S. Engemann, A. Pastore and E. E. Wanker, Nat. Struct. Mol. Biol., 2008, 15, 558-566.

14 P. K. Singh, V. Kotia, D. Ghosh, G. M. Mohite, A. Kumar and S. K. Maji, ACS Chem. Neurosci., 2013, 4, 393-407.

15 G. R. Lamberto, A. Binolfi, M. L. Orcellet, C. W. Bertoncini, M. Zweckstetter, C. Griesinger and C. O. Fernandez, Proc. Natl. Acad. Sci. U. S. A., 2009, 106, 21057-21062.

16 L. Breydo, J. W. Wu and V. N. Uversky, Biochim. Biophys. Acta, 2012, 1822, 261-285.

17 M. Perni, C. Galvagnion, A. Maltsev, G. Meisl, M. B. D. Müller, P. K. Challa, J. B. Kirkegaard, P. Flagmeier, S. I. A. Cohen, R. Cascella, S. W. Chen, R. Limbocker, P. Sormanni, G. T. Heller, F. A. Aprile, N. Cremades, C. Cecchi, F. Chiti, E. A. A. Nollen, T. P. J. Knowles, M. Vendruscolo, A. Bax, M. Zasloff and C. M. Dobson, Proc. Natl. Acad. Sci. U. S. A., 2017, 114, E1009-E1017.

18 N. N. Jha, R. Kumar, R. Panigrahi, A. Navalkar, D. Ghosh, S. Sahay, M. Mondal, A. Kumar and S. K. Maji, ACS Chem. Neurosci., 2017, 8, 2722-2733.

19 T. Ibrahim and J. McLaurin, Biochem. Biophys. Res. Commun., 2016, 469, 529-534.

20 A. A. Deeg, A. M. Reiner, F. Schmidt, F. Schueder, S. Ryazanov, V. C. Ruf, K. Giller, S. Becker, A. Leonov, C. Griesinger, A. Giese and W. Zinth, Biochim. Biophys. Acta, 2015, 1850, 1884-1890.

21 K. Ji, Y. Zhao, T. Yu, Z. Wang, H. Gong, X. Yang, Y. Liu and K. Huang, Food Funct., 2016, 7, 409-416.

22 N. Ahsan, S. Mishra, M. K. Jain, A. Surolia and S. Gupta, Sci. Rep., 2015, 5, 9862.

23 N. N. Jha, D. Ghosh, S. Das, A. Anoop, R. S. Jacob, P. K. Singh, N. Ayyagari, I. N. N. Namboothiri and S. K. Maji, Sci. Rep., 2016, 6, 28511.

24 N. Ahsan, I. A. Siddique, S. Gupta and A. Surolia, Eur. J. Med. Chem., 2018, 143, 1174-1184.

25 R. Chakraborty, S. Sahoo, N. Halder, H. Rath and K. Chattopadhyay, ACS Chem. Neurosci., 2019, 10, 573-587.

26 J. Pujols, S. Peña-Díaz, D. F. Lázaro, F. Peccati, F. Pinheiro, D. González, A. Carija, S. Navarro, M. Conde-Giménez, J. García, S. Guardiola, E. Giralt, X. Salvatella, J. Sancho, M. Sodupe, T. F. Outeiro, E. Dalfó and S. Ventura, Proc. Natl. Acad. Sci. U. S. A., 2018, 115, 10481-10486.

27 D. Yedlapudi, G. S. Joshi, D. Luo, S. V. Todi and A. K. Dutta, Sci. Rep., 2016, 6, 38510.

28 S. Ghosh, A. Kundu and K. Chattopadhyay, Sci. Rep., 2018, 8, 5481.

29 N. Joshi, S. Basak, S. Kundu, G. De, A. Mukhopadhyay and K. Chattopadhyay, Langmuir, 2015, 31, 1469-1478.

30 D. Ghosh, S. Mehra, S. Sahay, P. K. Singh and S. K. Maji, Int. J. Biol. Macromol., 2017, 100, 37-54.
31 H. Nedaei, A. A. Saboury, A. A. Meratan, L. Karami, L. Sawyer, B. Kaboudin, N. Jooyan and A. Ghasemi, J. Mol. Liq., 2018, 266, 291-298.

32 D. L. Melnikova, V. D. Skirda and I. V. Nesmelova, J. Phys. Chem. B, 2017, 121, 2980-2988.

33 T. Kuboyama, C. Tohda and K. Komatsu, Biol. Pharm. Bull., 2014, 37(6), 892-897.

34 S. Sivasankar, R. Lavanya, P. Brindha and N. Angayarkanni, PLoS One, 2015, 10(3), e0120512.

35 S. R. Varma, T. O. Sivaprakasam, A. Mishra, L. M. S. Kumar, N. S. Prakash, S. Prabhu and S. Ramakrishnan, PLoS One, 2016, 11(1), e0145921.

36 K. Lu, D. Chakroborty, C. Sarkar, T. Lu, Z. Xie, Z. Liu and S. Basu, PLoS One, 2012, 7(8), e43934.

37 N. Uabundit, J. Wattanathorn, S. Mucimapura and K. Ingkaninan, J. Ethnopharmacol., 2010, 127, 26-31.

38 M. S. Baliga, S. Meera, B. Mathai, M. P. Rai, V. Pawar and P. L. Palatty, Chin. J. Integr. Med., 2012, 18, 946-954.

39 D. P. Singh, R. Govindarajan and A. K. Rawat, Phytochem. Anal., 2008, 19, 164-168.

40 V. Pawar, P. Lahorkar and D. B. Ananthanarayana, Indian J. Pharm. Sci., 2009, 71, 382-386.

41 S. Cheriyamundath, T. Mahaddalkar, S. N. Save, S. Choudhary, R. V. Hosur and M. Lopus, Biomed. Pharmacother., 2018, 98, 76-81.

42 R. Jakes, M. G. Spillantini and M. Goedert, FEBS Lett., 1994, 345, 27-32.

43 M. J. Volles and P. T. Lansbury Jr, J. Mol. Biol., 2007, 366, 1510-1522.

44 D. Marion, M. Ikura, R. Tschudin and A. Bax, J. Magn. Reson., 1989, 85, 393-399.

45 J. G. Reddy and R. V. Hosur, J. Biomol. NMR, 2014, 59, 199210.

46 C. Bodner, A. S. Maltsev, C. Dobson and A. Bax, Biochemistry, 2010, 49, 862-871.

47 J. Cavanagh, W. J. Fairbrother, A. G. I. Palmer, M. Rance and N. J. Skelton, Protein NMR Spectroscopy: Principles and Practice, Elsevier Inc., 2nd edn, 2007.

48 M. Biancalana and S. Koide, Biochim. Biophys. Acta, 2010, 1804(7), 1405-1412.

49 M. R. H. Krebs, E. H. C. Bromley and A. M. Donald, J. Struct. Biol., 2005, 149, 30-37.

50 C. Xue, T. Y. Lin, D. Chang and Z. Guo, R. Soc. Open Sci., 2017, 4, 160696.

51 M. F. Bishop and F. A. Ferrone, Biophys. J., 1984, 46, 631-644. 52 A. Micsonai, F. Wien, L. Kernya, Y. H. Lee, Y. Goto, M. Refregiers and J. Kardos, Proc. Natl. Acad. Sci. U. S. A., 2015, 112, E3095-E3103.

53 A. Micsonai, F. Wien, E. Bulyaki, J. Kun, E. Moussong, Y. H. Lee, Y. Goto, M. Refregiers and J. Kardos, Nucleic Acids Res., 2018, 46, W315-W322.

54 M. Sandal, F. Valle, I. Tessari, S. Mammi, E. Bergantino, F. Musiani, M. Brucale, L. Bubacco and B. Samori, PLoS Biol., 2008, 6(1), e6.

55 H. Yu, W. Han, W. Ma and K. Schulten, J. Chem. Phys., 2015, 143, 243142. 
56 M. S. Celej, R. Sarroukh, E. Goormaghtigh, G. D. Fidelio, J. M. Ruysschaert and V. Raussens, Biochem. J., 2012, 443, 719-726.

57 D. Ghosh, P. K. Singh, S. Sahay, N. N. Jha, R. S. Jacob, S. Sen, A. Kumar, R. Riek and S. K. Maji, Sci. Rep., 2015, 5, 9228.

58 M. P. Williamson, Prog. Nucl. Magn. Reson. Spectrosc., 2013, 73, 1-16.

59 D. Bhattacharyya, R. Kumar, S. Mehra, A. Ghosh, S. K. Maji and A. Bhunia, Chem. Commun., 2018, 54, 3605-3608.

60 L. Giehm, D. I. Svergun, D. E. Otzen and B. Vestergaard, Proc. Natl. Acad. Sci. U. S. A., 2011, 108, 3246-3251.

61 N. Zijlstra, C. Blum, I. M. J. Segers-Nolten, M. M. A. E. Claessens and V. Subramaniam, Angew. Chem., Int. Ed., 2012, 51, 8821-8824.

62 W. Paslawski, S. Mysling, K. Thomsen, T. J. D. Jørgensen and D. E. Otzen, Angew. Chem., Int. Ed., 2014, 53, 7560-7563.

63 G. M. Mohite, R. Kumar, R. Panigrahi, A. Navalkar, N. Singh, D. Datta, S. Mehra, S. Ray, L. G. Gadhe, S. Das, N. Singh, D. Chatterjee, A. Kumar and S. K. Maji, Biochemistry, 2018, 57, 5183-5187.

64 J. I. Gallea and M. S. Celej, J. Biol. Chem., 2014, 289, 2673326742.

65 N. Lorenzen, S. B. Nielsen, A. K. Buell, J. D. Kaspersen, P. Arosio, B. S. Vad, W. Paslawski, G. Christiansen, Z. Valnickova-Hansen, M. Andreasen, J. J. Enghild, J. S. Pedersen, C. M. Dobson, T. P. J. Knowles and D. E. Otzen, J. Am. Chem. Soc., 2014, 136, 3859-3868.

66 N. Cremades, S. I. A. Cohen, E. Deas, A. Y. Abramov, A. Y. Chen, A. Orte, M. Sandal, R. W. Clarke, P. Dunne, F. A. Aprile, C. W. Bertoncini, N. W. Wood, T. P. J. Knowles, C. M. Dobson and D. Klenerman, Cell, 2012, 149, 1048-1059.
67 S. W. Chen, S. Drakulic, E. Deas, M. Ouberai, F. A. Aprile, R. Arranz, S. Ness, C. Roodveldt, T. Guilliams, E. J. DeGenst, D. Klenerman, N. W. Wood, T. P. J. Knowles, C. Alfonso, G. Rivas, A. Y. Abramov, J. M. Valpuesta, C. M. Dobson and N. Cremades, Proc. Natl. Acad. Sci. U. S. A., 2015, 112, E1994-E2003.

68 G. Fusco, S. W. Chen, P. T. F. Williamson, R. Cascella, M. Perni, J. A. Jarvis, C. Cecchi, M. Vendruscolo, F. Chiti, N. Cremades, L. Ying, C. M. Dobson and A. D. Simone, Science, 2017, 358, 1440-1443.

69 J. A. Varela, M. Rodrigues, S. De, P. Flagmeier, S. Gandhi, C. M. Dobson, D. Klenerman and S. F. Lee, Angew. Chem., Int. Ed., 2018, 57, 4886-4890.

70 H. Kumar, J. Singh, P. Kumari and J. B. Udgaonkar, J. Biol. Chem., 2017, 292(41), 16891-16903.

71 B. D. van Rooijen, M. M. Claessens and V. Subramaniam, Biochim. Biophys. Acta, 2009, 1788(6), 1271-1278.

72 B. D. van Rooijen, K. A. van Leijenhorst-Groener, M. M. Claessens and V. Subramaniam, J. Mol. Biol., 2009, 394, 826-833.

73 S. Mysling, C. Betzer, P. H. Jensen and T. J. D. Jorgensen, Biochemistry, 2013, 52, 9097-9103.

74 H. Y. Kim, M. K. Cho, A. Kumar, E. Maier, C. Siebenhaar, S. Becker, C. O. Fernandez, H. A. Lashuel, R. Benz, A. Lange and M. Zweckstetter, J. Am. Chem. Soc., 2009, 131, 17482-17489.

75 A.-C. Hoffmann, G. Minakaki, S. Menges, R. Salvi, S. Savitskiy, A. Kazman, H. V. Miranda, D. Mielenz, J. Klucken, J. Winkler and W. Xiang, Sci. Rep., 2019, 9, 544. 76 S. N. Save and S. Choudhary, RSC Adv., 2017, 7, 20460.

77 M. Vilar, H. T. Chou, T. Luhrs, S. K. Maji, D. R. Loher, R. Verel, G. Manning, H. Stahlberg and R. Riek, Proc. Natl. Acad. Sci. U. S. A., 2008, 105, 8637-8642. 